\title{
How to write an integrative review: contextualization in the health care of the elderly
}

\begin{abstract}
The objective was to analyze the contextualization of healthy aging from the point of view of Brazilian scientific production. Method: integrative review conducted in the LILACS, MEDLINE, BDENF and SciELO virtual libraries in the studies published in the period from 2008 to 2018, guided by the question: How is the term healthy aging contextualized in Brazil? It was observed that there was a diversity of concepts that managed the construction of knowledge in the face of the conditions that determined it as a current paradigm in Brazilian society. How is the term healthy aging contextualized in Brazil? It was observed that there was a diversity of concepts that managed the construction of the knowledge before the conditions that determined it as a current paradigm in Brazilian society.
\end{abstract}

Keywords: aging, nursing, health, gerontology, care
Volume 3 Issue 6 - 2018

\author{
Trigueiro EV, Santos APS, Diniz ERS, Bezerra \\ ARB, Rocha ATS, Fernandes SDM, Diniz \\ GMD, Bitencourt MLS, Nusk SD, Alves ABR \\ Universidade Federal do Rio Grande do Norte, Nurses \\ Researchers in Geriatrics and Gerontology, Brazil
}

\begin{abstract}
Correspondence: Elizabeth Vasconcelos Trigueiro, Universidade Federal do Rio Grande do Norte, Nurses Researchers in Geriatrics and Gerontology, Brazil, Email nursing_scientist@hotmail.com
\end{abstract}

Received: December 14, 2018 | Published: December 18 2018

\section{Introduction}

The increase in the elderly population between researchers, social and political issues in various countries around the world. The current demographic transition refers to continuous pursuit of goal setting and public policies aimed at the aging with health maintenance, guarantee of quality of life and absence of disabilities. The term aging is seen, at present, as a paradigm to be contextualized by many researchers in gerontology and other áreas of knowledge that seek ways to manage means of achieving it. ${ }^{1,2}$

The predictions of changes in the age pyramids of Brazil over a period of 50 years show that, in 2050, the number of elderly people ( $\geq 80$ years) will surpass that of children $<4$ years. From 2006 to 2007 , the number of people $>40$ years grew by $4.2 \%$ and that of people $>60$ years grew by $10.5 \%{ }^{3}$

Faced with the increase in the demographics of older people foreseen for the recent years, longevity can only be considered as a real achievement of society as it adds quality to the additional years of life. Any policy aimed at the elderly must take into account functional capacity and the need for autonomy, participation, care and selfsatisfaction. It should also consider the performance of the elderly in different social contexts and the development of new meanings for advanced life, in order to encourage healthy aging. ${ }^{4}$

It is noteworthy that there are several theories that try to explain the aging process and try to find, in a way, ways to reach it within the perspective of health and quality of life. The production of knowledge takes place between biological, physiological, psychological and social theories that are accepted, corrected or rejected, within a process of continuous construction that supports the attendance to this so complex phase of the life cycle. ${ }^{5}$

Healthy aging assumes a broader conception than the absence of disease, being considered a process of adaptation to the changes that occur throughout life, which allows the elderly to maintain their physical, mental and social well-being, being this term strongly related to the maintenance of good old age and the identification of its determinants. ${ }^{6}$

It is known that health education groups promote learning about healthy behaviors, stimulate the autonomy of the elderly, improve self-esteem, promote a better quality of life and provide the social insertion of the participants, and also contribute to the construction of spaces of conviviality and reflection before the needs of its members. ${ }^{7}$

Healthy aging has spawned changes that drive researchers around the world to take a multidimensional approach between aging and health in its biological, psychological and social aspects. The term healthy or successful aging is defined through a series of criteria (life satisfaction and mood disposition), as well as health indicators (morbidity and mortality) that describe it as the ability to maintain quality versus three basic characteristics : low risk of disease and deficiencies related to the disease; high mental and physical activity; and active involvement in everyday life. ${ }^{8}$

Aging has managed, mainly in the scenario of scientific production, the search for quality of life associated with longevity. It is verified that the theme has been explored more in the health area due to the demographic explosion in the world, especially in developing countries as it is the case of Brazil, that ages within the context of the social inequalities. ${ }^{9}$

This study is justified by the need to explore the broad theme, the needs of nursing and the scientific methodology.

\section{Method}

The present study was an integrative literature review. This method has the purpose of grouping and synthesising research results on a given topic, in an organized way so that it contributes to a deepening of the knowledge about the question addressed..$^{10}$ This method has been used in the production of articles, dissertations and theses in the health area in recent decades. 
An integrative review of the literature on the scientific production, in the national and international context, in the health area was carried out. This method allows " [...] the search, the critical evaluation and the synthesis of the available evidence of the subject investigated". ${ }^{10}$ The use of this method allows as a result the current situation of knowledge about the topic addressed, the implementation of interventions in health care and the identification of gaps that need further study in the subject.

For the elaboration of this study, the six stages of the integrative review were used, as cited by Mendes et al. ${ }^{10}$ in order to organize the collected information. ${ }^{10}$

1st stage: elaboration of the guiding question. Its definition is the most important phase because it determines the identification of what should be approached to contemplate the proposed theme. ${ }^{10}$

2nd stage: search or sampling in the literature. The search was carried out in a wide and diversified way in the reliable databases, taking into account that the determination of inclusion and exclusion criteria for material selection should be carried out in accordance with the guiding question. ${ }^{10}$

Step 3: Data collection. At this stage we defined what would be extracted from the selected studies through the use of a previously elaborated instrument, with the purpose of organizing the key information in a concise way for the construction of the study. ${ }^{10}$

Step 4: Critical analysis of included studies. At this stage, data analysis was performed in detail to ensure the validity of the review. Always taking into account the guiding question as the basis for any analysis of the study. ${ }^{10}$

Step 5: discussion of results. In this phase the results obtained in the research were discussed and a critical analysis was carried out on what was evidenced. ${ }^{10}$

Step 6: presentation of the integrative review. This is the stage in which the study was duly elaborated. ${ }^{10}$ Containing enough information for the reader to make an analysis of the study carried out (Figure 1). ${ }^{10}$

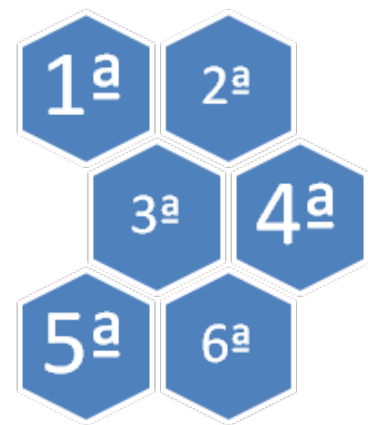

Figure I Elaboration of six stages of the integrative review.

The research universe consisted of online articles in the health field related to geriatrics and gerontology, through access to the VHL database. The sample was determined considering the following inclusion criteria: they are available in the selected databases, contemplate the proposed theme, are available in full text, are publications of the type article, from 2008 to 2018. The exclusion criteria were: dissertations and theses, are in Spanish, as well as complete texts unavailable and do not contemplate the proposed theme. ${ }^{10}$
A total of 487 articles were found, of which 19 were used to carry out this brief review. The data of the studies included in the research were categorized, analyzed and discussed, establishing relationships with the theoretical basis in focus. ${ }^{10}$

\section{Results and discussion}

It was observed that, unanimously, all articles placed healthy aging in the multidimensional perspective (among biological, social, psychological and physical aspects). There was a symbolic generalization of the term when used in the production of knowledge, determining a line of thought that provided the reflection of the aging process in relation to the maintenance and pursuit of autonomy, improvement of the quality of life (in the broader conception) and health taking into account not only the absence of diseases, but all the biopsychosocial well-being foreseen in the conceptualization of the term), within the maximum limit of physical possibilities of the human being. ${ }^{11}$

Most of the studies analyzed presented the understanding of aging as a benign and non-pathological process, being a process that is, to a certain extent, modifiable. Working with the approach of healthy aging provides, above all, the visualization and defense of the elderly in the family and in society, in a participatory, constructive and involving social inclusion in all aspects. This is one of the important missions of those who dedicate themselves to the proposal of comprehensive and humane remedial basic care. One should not only accept the longevity of the human being as the main achievement of contemporary humanity, but rather, that this human being has guaranteed a life with quality, happiness, active participation in its environment and social insertion. ${ }^{12}$

There is a risk of using the term healthy aging in relation to the term health vulnerability. Health vulnerability is understood as an appropriate concept to stimulate social responses and it has no direct application to issues involving only health in old age, but the elderly as a citizen of rights and who has the same right to grow up healthy. On this occasion, the authors suggested that concepts should be approached in order to confront the social determinants and solution of social problems addressed by the elderly, in order to guarantee the valuation of the elderly in different contexts and also as subjects of rights and, in the community, as co-responsible for the promotion of healthy, successful aging. ${ }^{13}$

Well-being in old age, or health, is demonstrated in the participation of the elderly in social, economic, spiritual, cultural and civil activities. The term is seen as the result of the balance between the various dimensions of the functional capacity of the elderly, without necessarily signifying the absence of problems in all dimensions. 8 Healthy aging, also called successful aging, prioritizes low risk of diseases and of functional disabilities related to them, mental and physical functioning and active involvement with life. ${ }^{14}$

Wisdom is another important aspect addressed when the theme is aging. As a paradigm nowadays, healthy aging needs to be more explored in scientific productions, since its multidimensions during the course of life and its repercussions in several fields of the subject's life cycle are broad themes that need to be deepened from the point of view of health and not of disease. ${ }^{15}$

The concept of the World Health Organization for healthy aging, as the process of optimizing health, participation and safety opportunities to improve quality of life in older people, is also contextualized 
among Brazilian scientific production. Quality of life is understood as the perception of the subject in relation to life within the context of the culture and value system in which he lives and in relation to his goals, expectations, standards and concerns. ${ }^{16,17}$

Understanding what constitutes good aging and its concept has become a form of reaction to the association between old age, loss, damage, and inactivity. The use of models and theories of health promotion facilitates the understanding of the determinants of health problems and the orientation of solutions that respond to the needs and interests of the elderly. At the same time, these models and theories contribute to the promotion of knowledge, reflection and decision in the acts of caring and acting, favoring the reach of health in the aging process. ${ }^{18,19}$

\section{Conclusion}

Contextualizing healthy aging as a paradigm in Brazilian scientific production is, above all, to try to find ways to achieve it and stimulate public policies in favor of an adequate health and quality of life for the entire population. Thus, this concept will surpass academic limits and will become a social reality within the panorama of integral health care for aging people, seeking ways to recognize the elderly as a citizen with socially recognized rights and duties.

It is perceived in the analyzed scientific production a complexity in the elaboration of factors that lead a society to reach longevity with total well-being and preserved autonomy. However, from this production, healthy aging is understood as a consequent process for the balance of functional capacity, cognitive function, memory, happiness, autonomy, lifestyle, individual construction and affective and social dynamics. It is worth noting that studies have been concerned with the dynamics of reaching the so-called healthy aging, taking into account the multidimensionality of factors (social, biological, physical and psychological) that facilitate their reach by the individual, family, community and of managements that involve public policies.

\section{Acknowledgments}

None.

\section{Conflicts of interests}

The authors of this manuscript have no competing interests.

\section{References}

1. Florêncio RS, Oliveira ACA, Santiago ACS, et al. Body and health perception for obesity in young adults. International Archives of Medicine. 2018:(11).

2. Amaral AKFJ, Vasconcelos AKM, Freitas AZVM, et al. Trends In geriodontics publication: a specialty emerging in brazil. International Archives of Medicine. 2017;10.
3. Koch HR Filho, Koch LFA, Bisinelli JC, et al. Uma década de odontogeriatria brasileira. Arch Oral Res. 2011;7(3):295-310.

4. Tahan J, Carvalho ACD. Reflexões de idosos participantes de grupos de promoção de saúde acerca do envelhecimento e da qualidade de vida. Saúde Soc. 2010;19(4):878-888.

5. Tramontino, VS Nuñez JMC, Takahashi JMFK, et al. Nutrição para idosos. Revista de Odontologia da USP. 2009;21(3):258-267.

6. Freese E. Epidemiologia, políticas e determinantes das doenças crônicas não transmissíveis no Brasil. Recife: Editora Universitária da UFPB;2006.

7. Borges CL, Silva MJ, Clares JWB, et al. Frailty assessment of institutionalized elderly. Acta Paul Enferm. 2013;26(4):318-322.

8. Díaz TF, Nazzal NC, Verdejo H, et al. Frailty in patients admitted to hospital with acute decompensated heart failure. Rev Med Chil. 2017;45(2):164 171 .

9. Maciel GMC, Silva HTA, Gonçalves RG, et al. Frailty assessment and its association with sociodemographic and health characteristics in community elderly. Int Arch Med. 2017;10(134).

10. Mendes KDS, Silveira RCCP, Galvão CM. Revisão integrativa: método de pesquisa para a incorporação de evidências na saúde e na enfermagem. Texto e contexto enferm, Florianópolis. 2008;17.

11. Linck CL, Crossetti, MGO. Fragility in the elderly: what has being produced by nursing. Rev Gaúcha Enferm. 2011;32(2):385-393.

12. Mello AC, Engstrom EM, Alves LC. Health-related and socio-demographic factors associated with frailty in the elderly: a systematic literature review. Cad Saúde Pública. 2014;30(6):1143-1168.

13. Nguyen TN, Morel KMC, Pepperell D, et al. The impact of frailty on coagulation and responses to warfarin in acute older hospitalised patients with atrial fibrillation: a pilot study. Aging Clin Exp Res. 2017;29(6):11291138

14. Brasil. Lei 8842, de 04 de janeiro de 1994. Dispõe sobre a política nacional do idoso, cria o conselho nacional do idoso e dá outras providências; 2018.

15. Hebling E, Rodrigues CK. O estatuto do idoso e a saúde bucal. Robrac. 2006;15(39):51-56.

16. Ribeiro PCC, Neri AL, Cupertino APFB, et al. Variabilidade no envelhecimento ativo segundo gênero, idade e saúde. Psicologia em estudo. 2009;14(3):501-509.

17. Gardner PJ. Envelhecimento saudável: uma revisão das pesquisas em língua inglesa. Movimento [Internet]. 2006;12(2):69-92.

18. Tamai SAB, Paschoal SMP, Litvoc J, et al. Impacto of a program to promote health and quality of life of elderly. Einstein. 2011;9(1):8-13.

19. Ministério da Saúde(BR). Estatuto do idoso/ministério da saúde. Brasília: Ministério da Saúde; 2003. 